Review

\title{
Licorice (Glycyrrhiza glabra, G. uralensis, and G. inflata) and Their Constituents as Active Cosmeceutical Ingredients
}

\author{
Antonietta Cerulli, Milena Masullo, Paola Montoro (D) and Sonia Piacente *
}

check for updates

Citation: Cerulli, A.; Masullo, M. Montoro, P.; Piacente, S. Licorice (Glycyrrhiza glabra, G. uralensis, and G. inflata) and Their Constituents as Active Cosmeceutical Ingredients. Cosmetics 2022, 9, 7. https://doi.org/ $10.3390 /$ cosmetics 9010007

Academic Editor: Piera Di Martino

Received: 29 November 2021

Accepted: 31 December 2021

Published: 5 January 2022

Publisher's Note: MDPI stays neutral with regard to jurisdictional claims in published maps and institutional affiliations.

Copyright: (C) 2022 by the authors. Licensee MDPI, Basel, Switzerland. This article is an open access article distributed under the terms and conditions of the Creative Commons Attribution (CC BY) license (https:// creativecommons.org/licenses/by/ $4.0 /)$.
Dipartimento di Farmacia, Università degli Studi di Salerno, Via Giovanni Paolo II n. 132, 84084 Fisciano, Italy; acerulli@unisa.it (A.C.); mmasullo@unisa.it (M.M.); pmontoro@unisa.it (P.M.)

* Correspondence: piacente@unisa.it
Abstract: The interest in plant extracts and natural compounds in cosmetic formulations is growing. Natural products may significantly improve cosmetics performance since they have both cosmetic and therapeutic-like properties, known as cosmeceutical effects. Glycyrrhiza genus, belonging to the Leguminosae family, comprises more than 30 species, widely distributed worldwide. The rhizomes and roots are the most important medicinal parts currently used in pharmaceutical industries and in the production of functional foods and food supplements. In the last few years, the interest in their potential activities in cosmetic formulations has greatly increased. Glycyrrhiza spp. extracts are widely implemented in cosmetic products for their good whitening effect. The biological effects of Glycyrrhiza extracts are especially ascribable to the occurrence of specialized metabolites belonging to the flavonoid class. This review focuses on the botany and the chemistry of the main investigated Glycyrrhiza spp. (G. glabra, G. uralensis, and G. inflata) along with their cosmeceutical activities categorized as skin anti-aging, photoprotective, hair care, and anti-acne. It has been highlighted how, along with Glycyrrhiza extracts, three main flavonoids namely licochalcone A, glabridin, and dehydroglyasperin $\mathrm{C}$ are the most investigated compounds. It is noteworthy that other molecules from licorice show potential cosmeceutical effects. These data suggest further investigations to clarify their potential value for cosmetic industries.

Keywords: Glycyrrhiza; licorice; cosmeceutical; glabridin; skin anti-aging; photoprotective activity; hair care; anti-acne activity

\section{Introduction}

Plant extracts and natural compounds derived from plants are considered valuable materials for the production of cosmetics. Natural products contained in cosmetic formulations may significantly contribute to an improvement of cosmetics performance. They can also be used as auxiliary substances enhancing the stability or bioavailability of cosmetic formulations [1]. Plants were the primary source of cosmetics before synthetic compounds, and now the trend of the cosmetic industry is to look more and more for natural active ingredients. This is due both to consumers' demand for more natural products and the global attention for environmentally friendly products. This means that new products containing herbs will continue to emerge on the market in the future [2]. The term "cosmeceutical" refers to cosmetics containing active chemicals with drug-like properties. Cosmeceuticals have beneficial local effects, prevent degenerative skin diseases, and improve skin tone. Cosmeceuticals are a growing sector of the personal care industry [2].

Glycyrrhiza genus, belonging to the Leguminosae family (also known as Fabaceae), consists of more than 30 species, widely distributed worldwide. The name "glycyrrhiza" derives from the Grecian words glykys and rhiza, which mean sweet and root, respectively [3]. It is also called licorice, liquorice, glycyrrhiza, sweet wood, and Liquiritiae radix [4]. Among the Glycyrrhiza spp., G. glabra L., G. uralensis Fisch., and G. inflata Bat. are the most investigated species with nutritional and pharmacological benefits, used as 
Radix Glycyrrhizae (licorice) [5]. They are also recorded in Chinese Pharmacopoeia as medicinal Glycyrrhiza plants [6]. Rhizomes and roots are the most important medicinal parts of licorice. They have been reported to be used alone or with other herbs to treat many digestive system disorders, respiratory tract disorders, epilepsy, fever, sexual debility, paralysis, rheumatism, leucorrhoea, psoriasis, prostate cancer, malaria, hemorrhagic diseases, and jaundice [3]. The extracts are currently used in pharmaceutical industries and in the manufacture of functional foods and food supplements $[4,7,8]$. Moreover, they can be used as a food and beverage flavoring agent [3]. Japan has a wide range of applications for the licorice chemical constituents, which occur 70\% in food products (glycyrrhizin), 26\% in medicinal cosmetics (glabridin), and $4 \%$ in tobacco, along with other uses [9].

Researchers focused their attention on exploring mainly G. glabra, G. uralensis, and G. inflata extracts and isolated pure compounds occurring as active ingredients for cosmetic purposes, based on their biological activities. Glycyrrhiza spp. extracts are currently used in cosmetic preparations due to their skin-whitening, anti-sensitizing, and anti-inflammatory properties [10]. Their use was widely implemented in commercial products, especially in cosmetic products, for its good whitening effect [11].

Several formulations containing licorice extracts are present in the market places. They are mostly used daily with SPF (Sun Protection Factor) products containing G. glabra root extract. The extract is incorporated in the internal aqueous phase of water/oleum emulsion in cream and serum formulations, claimed for their anti-aging activities, for their effects on wrinkles, on hyperpigmentation, and as skin lightening. For these effects, the licorice extracts are also used in the formulation of sunscreens and also for personal care products such as facial cleansers, make-up removers, toners, and shampoo. Moreover, make-up products such as foundations, concealers, around-the-eye creams, make-up primers, lipsticks, and $\mathrm{BB}$ creams contain licorice extract.

Reviews reported in the literature described the traditional uses, the chemistry, the chemotaxonomy, the pharmacological activities and the analysis of licorice extracts focusing mainly on G. glabra [3-6,11-13]. Herein, we describe briefly the botany and the chemistry of G. glabra, G. inflata, and G. uralensis focusing on the skin anti-aging, photoprotective, hair care, and anti-acne activities of extracts and bioactive compounds isolated from these species, never summarized before. In light of all the reports, the potential of licorice extracts and their specialized metabolites as constituents of cosmeceutical formulations is confirmed to be very promising.

\section{Botanical Description}

Glycyrrhiza spp. are herbaceous plants growing in the subtropical and temperate zone. The plants can reach a maximum height of up to $2 \mathrm{~m}$, while the underground stem can grow up to $2 \mathrm{~m}$ horizontally, generally in fertile and sandy ground [12]. The plants show pinnate leaves, narrow flowers, lavender to violet in color. The fruit is an oblong legume containing three-eight brown reniform seeds. The roots are well developed with a brown color. The pieces of roots break with a fibrous fracture and possess a typical aroma and a sweet taste [12,14]. The rhizomes and roots are harvested 3-4 years after the planting, washed to remove buds and rootlets, cut into small pieces, and finally dried [15]. G. glabra, G. inflata, and G. uralensis are significantly explored for nutritional and pharmacological benefits among the known species. Three varieties of G. glabra have been reported, grown in different regions and designated as G. glabra var. violacea (Persian and Turkish), G. glabra var. gladulifera (Russian), and G. glabra var. typica (Spanish and Italian) [12].

\section{Chemistry of Glycyrrhiza}

The $50 \%$ dry weight of licorice roots is due to water-soluble metabolites and sugars (5-15\% glucose, sucrose, and mannitol), starch (25-30\%), glycyrrhizin (10-16\%), amines (1-2\% asparagine, betaine, and choline), and sterols (stigmasterol and $\beta$-sitosterol) [12].

Thus far, more than 400 phytochemicals have been isolated from the genus Glycyrrhiza. These molecules can be classified as saponins, flavonoids, chromenes, coumarins, dihy- 
drostilbenes, coumestans, benzofurans, and dihydrophenanthrenes [4,5,12], among which flavonoids and triterpenoid saponins are abundant in the root or rhizome of licorice [5]. Generally, alkaloids and tannins were not detected [12]. Although the roots represent the most used parts, phytochemical investigations were also performed on the leaves, considered an agrochemical waste. These studies demonstrated that certain compounds present in the roots are also identified in the leaves of G. glabra leaves [16]. This section will discuss the flavonoids and triterpenoid saponins isolated in G. glabra, G. inflata, and G. uralensis, the three species investigated for their cosmetic effects, focusing on the main reported compounds and on compounds tested for the biological activities.

Along with these classes, a coumarin-derivative reported in G. glabra, and G. uralensis, licoarylcoumarin, will also be discussed for its properties.

\subsection{Flavonoids}

More than 300 compounds belonging to the class of flavonoids have been isolated and identified from licorice $[4,11]$. Flavonoids, generally formed by two benzene rings (A ring and $\mathrm{B}$ ring) through a central tri-carbon chain-generating $\mathrm{C}$ ring, are divided into flavonols, flavones, flavanones, flavanols, dihydro-flavones, chalcones, isoflavones, according to the occurrence of the $\mathrm{C}$ ring, its oxidation degree, and the connection site of the $\mathrm{B}$ ring. Several kinds of flavonoids are representative compounds isolated from G. glabra, G. uralensis, and G. inflata. The more representative flavonoids, tested for their cosmeceutical activities, have been categorized as flavanones, flavonols, flavones, isoflavanes, isoflavenes, isoflavones, and chalcones.

Liquiritin is one of the most abundant flavonoids and is used as a quantitative chemical marker in the three official medicinal licorice species in Chinese Pharmacopoeia [5]. It consists of liquiritigenin, a flavanone reported in Glycyrrhiza, linked to a $\beta$-D-glucopyranosyl residue at position 4' via a glycosidic linkage. Pinocembrin and liquiritin apioside, belonging to the flavanone class, have also been reported (Figure 1).

Flavanols such as kaempferol, pratensein, and the flavone chrysoeriol are herein discussed for their activity.

Glabridin is the principal isoflavane identified, ranging between $0.08 \%$ and $0.35 \%$ of G. glabra roots dry weight [4,17]. Chemically, glabridin is a prenylated isoflavane deemed a typical compound in G. glabra, accounting for $11 \%$ of its total flavonoid content [11]. Along with glabridin, licoricidin (also known as licorisoflavan B), hispaglabridin A, glyasperin $\mathrm{C}$, glyasperin $\mathrm{D}$, and $3^{\prime}$-hydroxy-4'-O-methylglabridin are mentioned. Isoflavenes as glabrene, dehydroglyasperin $\mathrm{C}$, dehydroglyasperin $\mathrm{D}$, isoflavones as glycyrrhisoflavone, semilicoisoflavone $\mathrm{B}$, allolicoisoflavone $\mathrm{B}$, isoangustone $\mathrm{A}$, and formononetin, as well as isoflavanones as dihydrodaidzein and glycyrrhisoflavanone were isolated from Glycyrrhiza spp. and tested for cosmeceutical properties. All the reported isoflavonoids, except formononetin, dihydrodaidzein, and pratensein are characterized by a prenyl moiety on ring $\mathrm{A}$ or ring $\mathrm{B}$, which can be free or involved in the formation of a pyran ring. In the case of glabridin, the prenyl chain at C-8 is involved in the formation of a pyran ring, but this latter can be fused either to the A ring or B ring of the isoflavonoid skeleton. Hispaglabridin A is characterized by a prenyl group cyclized to pyrene on the A ring and an additional prenyl function at the $B$ ring. The isoprenyl groups on the $A$ and $B$ rings make the flavonoid backbone more lipophilic, resulting in increased affinity with cell membrane structures and favorable biological activities (Figure 1) [11]. 


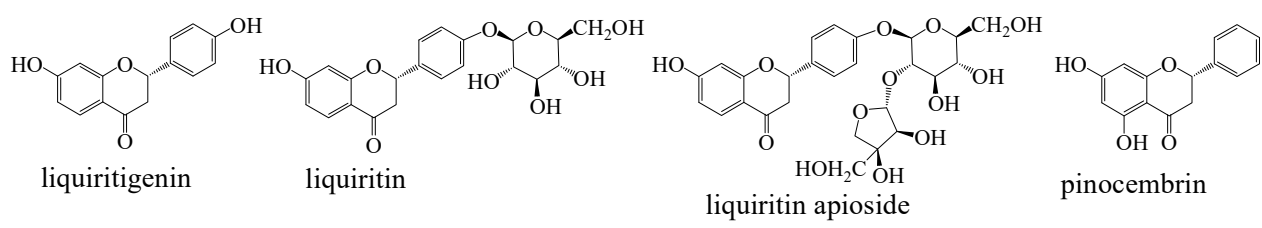

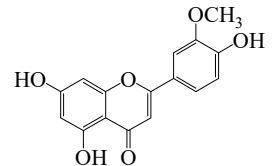

chrysoeriol<smiles>O=C1C=CC(O)CC1C1Oc2cc(O)ccc2OC1O</smiles>

kaempferol

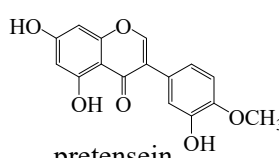

pretensein ${ }^{\mathrm{OH}}$

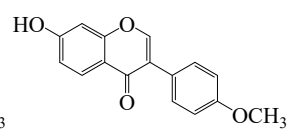

formononetin

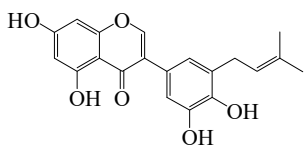

glycyrrhisoflavone

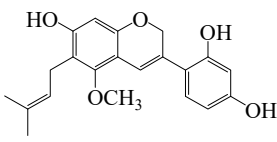

dehydroglyasperin $\mathrm{C}$

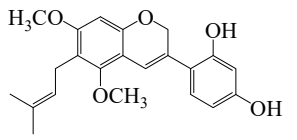

dehydroglyasperin D

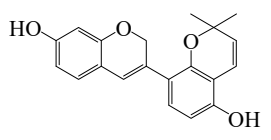

glabrene

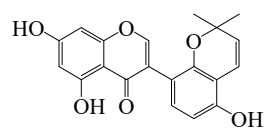<smiles>O=C1c2ccc(O)cc2OCC1c1ccc(O)cc1</smiles>

dihydrodaidzein

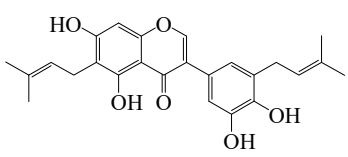

isoangustone $\mathrm{A}$

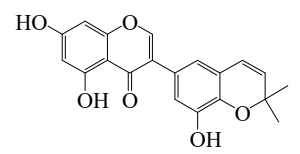

semilicoisoflavone B

allolicoisoflavone B

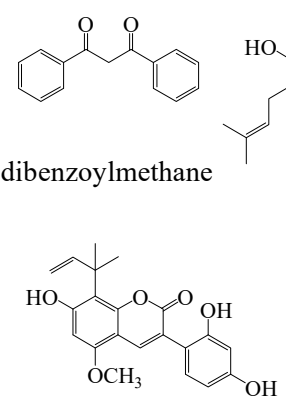

licoarylcoumarin

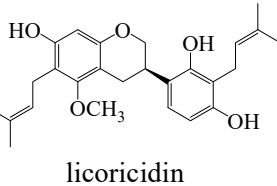

licoricidin

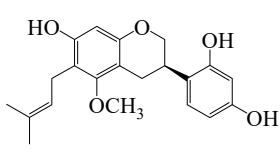

glyasperin $\mathrm{C}$

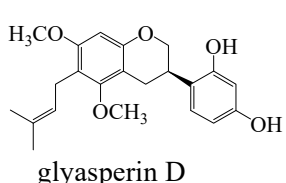

glyasperin D

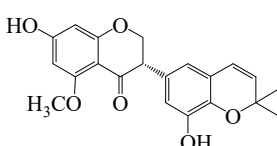

$\mathrm{OH}$

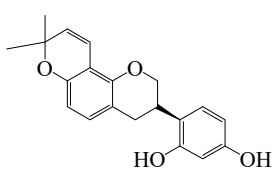

glabridin

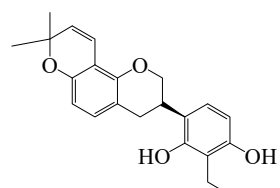

hispaglabridin A

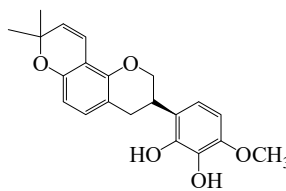

3'-hydroxy-4'-O-methylglabridin

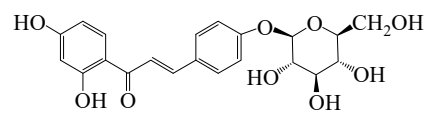

isoliquiritin

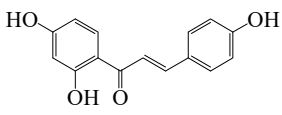

isoliquiritigenin
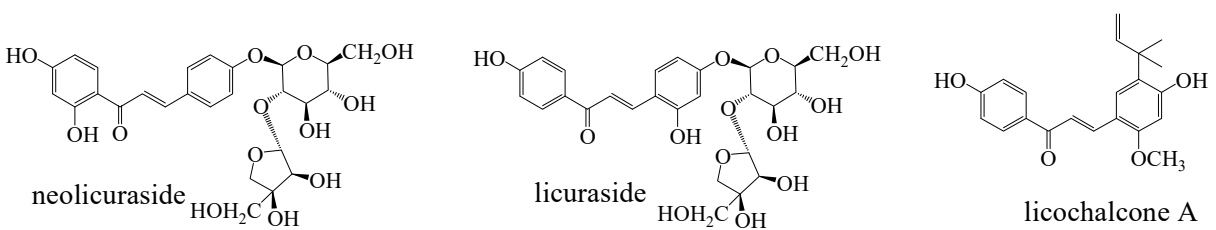

licochalcone A

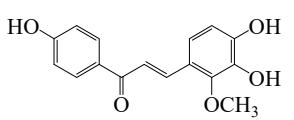

licochalcone $\mathrm{B}$

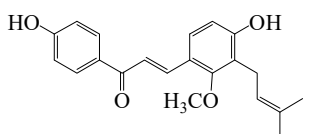

licochalcone $\mathrm{C}$

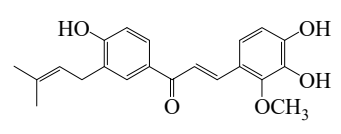

licochalcone D

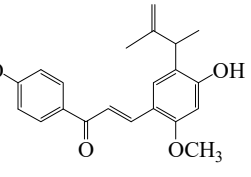

licochalcone $\mathrm{E}$

Figure 1. Flavonoid derivatives from Glycyrrhiza spp. as active ingredients for cosmetic formulations.

Chalcones are frequently reported in licorice roots; in this review the activities of isoliquiritigenin, isoliquiritin, licochalcone $\mathrm{A}$, licochalcone $\mathrm{B}$, licochalcone $\mathrm{C}$, licochalcone 
D, licochalcone E, licuraside, and neolicuroside are discussed. The dibenzoylmethane, a structural analogue of curcumin (diferuloylmethane) isolated from G. glabra, has also been investigated for its cosmetic properties.

Among the flavonoids previously cited, the main representative compounds of Glycyrrhiza are liquiritin ( $4^{\prime}, 7$-dihydroxyl flavone) and isoliquiritin $\left(2^{\prime}, 4^{\prime}, 4\right.$-trihydroxyl chalcone) glycosides (Figure 1).

\subsection{Saponins}

More than 70 saponins were isolated from Glycyrrhiza roots, and their structures have been shown in a recent review [13].

Among the oleanane triterpenoid saponins, glycyrrhizinic acid (also known as glycyrrhizic acid) or its salt glycyrrhizin has been reported as the major secondary metabolite found in the root of Glycyrrhiza spp.; this monodesmosidic saponin exhibits a $18 \beta$ glycyrrhetic acid skeletal structure, derived from $\beta$-amyrin, linked to a disaccharide unit made up of two glucuronic acid moieties at position C-3 [18]. Glycyrrhizin along with its aglycon, glycyrrhetic acid, are the most studied and abundant compounds from the roots of this plant. Glycyrrhetic acid exists as two isomers: $18 \alpha$-form and $18 \beta$-form. As a sweetener, glycyrrhizin is reported to be 30-50 times sweeter than sucrose [18]. Glycyrrhiza saponins, composed of aglycone and sugar moiety, can be classified into several classes, in which glucuronic acid, glucose, rhamnose are the major characteristic parts of sugar moiety [19]. Licorice saponin G2 (also known as 24-hydroxyglycyrrhizin) is shown below (Figure 2).

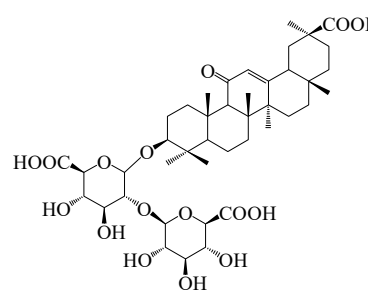

glycyrrhizinic acid

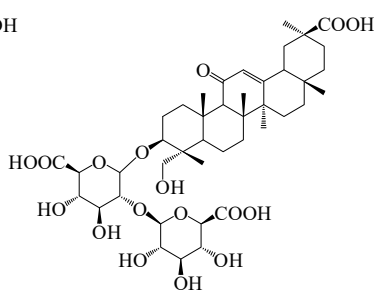

licorice saponin G2

Figure 2. Triterpenoid derivatives from Glycyrrhiza spp. as active ingredients for cosmetic formulations.

\subsection{Polysaccharides}

Among the bioactive ingredients of Glycyrrhiza plants, Glycyrrhiza polysaccharides are receiving more and more attention. A recent review reports their isolation, structural characterization, and biological activities [6]. They are heteropolysaccharides mainly composed of arabinose, glucose, galactose, rhamnose, mannose, xylose, and galacturonic acid in different proportions and types of glycosidic bonds. A preliminary study on the moisture retention of polysaccharides highlighted that their water retention ability was higher than that of glycerol solution, suggesting their potential use as a cosmetic moisturizing additive [6].

\subsection{Species-Specific Markers for G. glabra, G. inflata, and G. uralensis}

Several analytical methods have been developed to discriminate the chemical differences of G. glabra, G. inflata, and G. uralensis based on the occurrence or amount of specialized metabolites [5,20-23]. These works could provide helpful information to the industry about the choice of Glycyrrhiza species to use. An investigation was performed by a combined approach using GC-MS, LC-MS, and 1D NMR analysis. Compounds responsible for the discrimination among the three species were identified: glycyrrhizin, 4-hydroxyphenyl acetic acid, and glycosidic conjugates of liquiritigenin or isoliquiritigenin along with the amino acid cadaverine were described only in G. inflata [24]. The three species, identified by DNA barcodes, were further analyzed by LC/UV- or LC/MS/MSbased quantitative analysis, revealing 151 bioactive secondary metabolites, of which 27 were discovered able to differentiate the three species [20]. Principal Component Analy- 
sis (PCA) performed on ${ }^{1} \mathrm{H}$ NMR spectra, and UHPLC-UV chromatograms highlighted marked chemical differences among the Glycyrrhiza spp. [25]. An NMR-based metabolomics analysis, followed by PCA was also performed [26]. The metabolites licochalcone A and glabridin, which are discussed more in the next paragraphs, were indicated as specific metabolites of G. inflata, and G. glabra, respectively $[20,25]$. Indeed, G. uralensis and G. inflata roots did not contain glabridin, and therefore, glabridin is considered a unique species-specific marker for G. glabra [12]. Licochalcone A, abundant in G. inflata but present in small amounts in G. uralensis and G. glabra, along with the occurrence of licochalcone C, licochalcone $\mathrm{E}$, and licochalcone $\mathrm{D}$, represent a marker for G. inflata. So far, glycycoumarin, a metabolite reported in higher amounts in G. uralensis, in small amounts in G. inflata, and in trace amounts in G. glabra, is considered a species-specific metabolite for G. uralensis [12] A detailed report on the species-specific metabolite markers in different licorice species was recently published [12]. In light of all these reports, the metabolomic characterization should be associated with the identification and quantitation of several key markers rather than the only quantitative analysis of a single ubiquitous Glycyrrhiza constituent.

Different extraction methods have been developed for saponins or flavonoids from Glycyrrhiza species. They include maceration, countercurrent extraction, supercritical fluid extraction, extraction by ultrasonics, Soxhlet extraction, and microwave assisted extraction [5,27]. In this review, most of the cosmeceutical effects described afterward are attributed to the flavonoid constituents of Glycyrrhiza. Literature data revealed how methanol and ethanol aqueous solutions were the most commonly used solvents for the extraction of flavonoids [28]. Indeed a mixture of ethanol/water $(30: 70, v / v)$ used for an extraction time of $60 \mathrm{~min}$ under $50{ }^{\circ} \mathrm{C}$ of licorice gave a high recovery of glabridin (72.5\%) [28]. To enrich the licorice fractions in licochalcone A, methods including highspeed countercurrent chromatography and treatment by macroporous resin were used [29].

\section{Skin Anti-Aging}

The thinning epidermal layer and the loss of collagen and elastic fiber lead to wrinkle formation and cause aging. Aging occurs due to intrinsic factors like genetics, cellular metabolism, hormone, and metabolic processes, or extrinsic factors like sun exposure, smoking, diet, and pollution [30]. Many people have chosen natural herbs rather than plastic surgery or laser therapy to look younger and reduce complications in the last few years. Plants supply nutrients required for healthy skin, helping the biological functioning of the skin. In addition, phytochemicals derived from plants showed skin beneficial properties related to UV protection, anti-oxidant action, matrix protection, and skin hydration [31,32].

\subsection{Anti-Tyrosinase Activity and Hyperpigmentation Diseases}

Glycyrrhiza extracts and their compounds have shown beneficial effects to improve skin pigmentation. Melanin, synthesized in melanocyte cells by the melanogenesis process, is responsible for the color of the skin. Different factors play a role in the production and expression of melanin in the skin, such as exposure to UV radiation, genetic predisposition, melanocyte size leading to a difference in the amount of melanin produced per cell, as well as several diseases, including albinism, a genetic inability to produce melanin, and vitiligo, a progressive loss of melanocytes [33]. Alteration in melanin could bring hyperpigmentation or hypopigmentation; in particular, a low quantity of melanin can cause local vitiligo and post-traumatic hypopigmentation. Abnormal amounts of melanin deposits in specific sites of the skin cause abnormal skin-colored patches like solar lentigos, chloasma, freckles, and post-inflammatory hyperpigmentation [34,35].

Although different mechanisms are involved in the melanogenesis process, key enzymes responsible for melanin biosynthesis are the polyphenolic oxidase tyrosinases. Melanogenesis is the physiological process of melanin formation in which tyrosinase, a copper-dependent enzyme, initiates the first step [36]. In detail, melanogenesis is directly regulated by three enzymes: tyrosinase, tyrosinase-related protein TRP-1, and TRP-2. Tyrosinase catalyzes the conversion of L-tyrosine to L-DOPA and then to dopachrome, which 
is subsequently polymerized spontaneously to melanin via a series of reactions [37]; consequently, tyrosinase is responsible for skin hyperpigmentation. In the last few years, this enzyme became an essential target for skin-whitening effects and therapeutic interventions associated with melanin hyperpigmentation [38]. Thus, molecules acting as tyrosinase inhibitors play an important role in cosmetic products as skin-whitening agents and in the treatment of various dermatological disorders. Flavonoids are the most representative class among natural phenolic compounds acting as tyrosinase inhibitors [35]. Numerous plants, among which are Glycyrrhiza spp. and natural compounds, have been reported for tyrosinase inhibitory activity, and they are used in the treatment of skin pigmentation [34] (Figure 3). Among Glycyrrhiza spp., the most investigated species is represented by G. glabra. The extract of G. glabra roots is reported for its strong anti-melanogenic activity, tested by reduction of intracellular tyrosinase and melanin content in B16F10 melanoma cells. Methanol and ethyl-acetate extracts of licorice roots exhibited significant activity with low $\mathrm{IC}_{50}$ values (2.1 and $4.7 \mu \mathrm{g} / \mathrm{mL}$ ) [38]. Glycyrrhiza glabra extract was also compared to kojic acid, a molecule currently used as a tyrosinase inhibitor, commercially available. The extract inhibited tyrosinase activity by $78.45 \%$ while kojic acid inhibited it by $99.67 \%$. Unfortunately, kojic acid has the disadvantage of being unstable during storage; G. glabra did not show any disadvantages during tyrosinase inhibition, suggesting a possible use of licorice extract in cosmetic formulations [10]. Along with the effects shown by the licorice extracts, secondary metabolites isolated from G. glabra leaves and roots showed anti-melanogenesis activity. Flavonoids occurring in Glycyrrhiza are reported for their anti-tyrosinase activity.

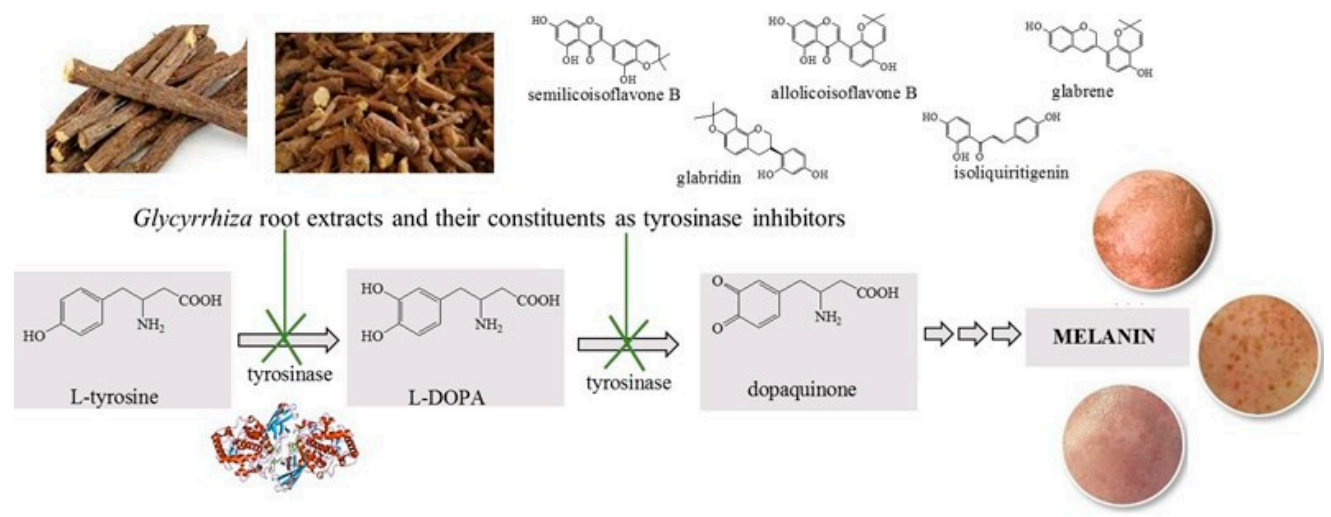

Figure 3. Skin depigmentation effect of Glycyrrhiza root extracts and their constituents by inhibition of tyrosinase enzyme.

Glabridin showed anti melanogenesis activity due to its tyrosinase inhibitory activity. The structure-activity relationship study highlighted how the hydroxyl groups at 2 and 4 positions seem responsible for the activity. Glabridin inhibited tyrosinase activity in cultured B16 murine melanoma cells at 0.1 to $1.0 \mu \mathrm{g} / \mathrm{mL}$, without affecting DNA synthesis [39]. It quenched the intrinsic fluorescence of tyrosinase mainly through a static quenching procedure, suggesting a generation of a stable glabridin-tyrosinase complex. Molecular docking calculations were performed to establish the interaction of glabridin with the tyrosinase enzyme. The results indicated that glabridin did not directly bind to the active site of tyrosinase [40]. To increase the glabridin water solubility, Hespeler et al. reported the use of smartPearls technology, aimed at improving dissolution velocity in the formulations. Glabridin smartPearls displayed a promising perspective if compared to glabridin raw drug powder, for creating skin products with improved dermal bioavailability [41]. All the features of glabridin smartPearls make it promising for skincare products with improved glabridin efficacy by simultaneously reducing production costs [41].

Other active compounds, such as glabrene, isoliquiritigenin, licuraside, isoliquiritin, and licochalcone $\mathrm{A}$, isolated from licorice extracts, were also shown to inhibit tyrosinase activity [39]. In particular, glabrene and isoliquiritigenin inhibited both mono- and diphenolase tyrosinase activities. The $\mathrm{IC}_{50}$ values for glabrene and isoliquiritigenin were 3.5 
and $8.1 \mu \mathrm{M}$, respectively, when tyrosine was used as substrate. The effects of glabrene and isoliquiritigenin on tyrosinase activity were dose-dependent and correlated to their ability to inhibit melanin formation in melanocytes [42].

Pinocembrin, the main compound in G. glabra leaves, is reported to have a moderate inhibitory effect on mushroom tyrosinase [43].

Lin and coworkers reported semilicoisoflavone B, allolicoisoflavone B, and glabridin for their noticeable tyrosinase inhibitory activities with $\mathrm{IC}_{50}$ of $0.25,0.80,0.10 \mu \mathrm{M}$, respectively [44]. Successively, Liu et al. developed a method using tyrosinase immobilized magnetic fishing coupled with high performance liquid chromatography-diode array detector-tandem mass spectrometry (IMF-HPLC-DAD-MS/MS) to screen and identify tyrosinase binders from $G$. uralensis root without isolation of secondary metabolites by the complex extract. Secondary metabolites of G. uralensis root such as liquiritin apioside, neolicuroside, liquiritigenin, licorice saponin G2, chrysoeriol, dihydrodaidzein, formononetin, glycyrrhisoflavanone, glycyrrhizinic acid, licoarylcoumarin, and pratensein showed the capacity to inhibit tyrosinase activity [45].

Literature reports how dehydroglyasperin C could be considered a whitening ingredient against hyperpigmentation in the skin. Dehydroglyasperin $\mathrm{C}$ decreased in a dose-dependent manner intracellular tyrosinase activity and expression of proteins related to melanin synthesis (TYR and TRP-1) in keratinocytes treated with $\alpha$-MSH (melanocyte stimulating hormone) to induce melanogenesis [46]. A series of licochalcones, consisting of licochalcone A, B, C, and E, normally isolated from the roots of G. inflata, showed tyrosine phosphatase 1B (PTP1B) inhibitory activities [11].

Multiple signaling pathways involved in melanogenesis were extensively described by Maddaleno et al., specifically in the regulation of the microphthalmia-associated transcription factor (MITF) [47]. MITF is a basic helix-loop-helix leucine zipper that regulates the expression of melanogenic enzymes (tyrosinase, TYRP1, and TYRP2) and melanosome structural proteins (MART-1 and PMEL17) [5].

Dehydroglyasperin $\mathrm{C}$ also reduced the downregulation of MITF (melanocyte-specific transcription factor) through suppression of cAMP-CREB pathway. Phosphorylation of extracellular signal-regulated kinase (ERK) also decreased MITF by dehydroglyasperin C treatment [46].

Licochalcone A inhibited melanogenesis through MAPK/ERK pathway by activating ERK. The MAP kinase family also regulates melanogenesis; phosphorylated p38 can activate microphthalmia-associated transcription factor (MITF), promoting melanin synthesis, whereas phosphorylated ERK can inhibit the activation of MITF.

A formulation of liquiritin cream (20\% of liquiritin) applied at $1 \mathrm{~g} /$ day for 4 weeks showed therapeutical effectiveness in melasma disease. However, this study suggests that liquiritin probably did not affect tyrosinase, which caused depigmentation by other mechanisms [48].

\subsection{Skin Lightening Activity}

Disorders of hyperpigmentation, including post inflammatory hyperpigmentation, skin problems such as freckles, age spots, acne scars, discoloration related to hormones, and skin exposure to sunlight, could induce skin pigmentation disorders. These pigmentary skin disorders, such as melasma, can have a consequent psychosocial impact. Skin lightening creams represent the products that work on skin by reducing melanin. Skin lightening products are also known as whiteners for naturally dark skin and skin brighteners (Figure 4) [49]. 


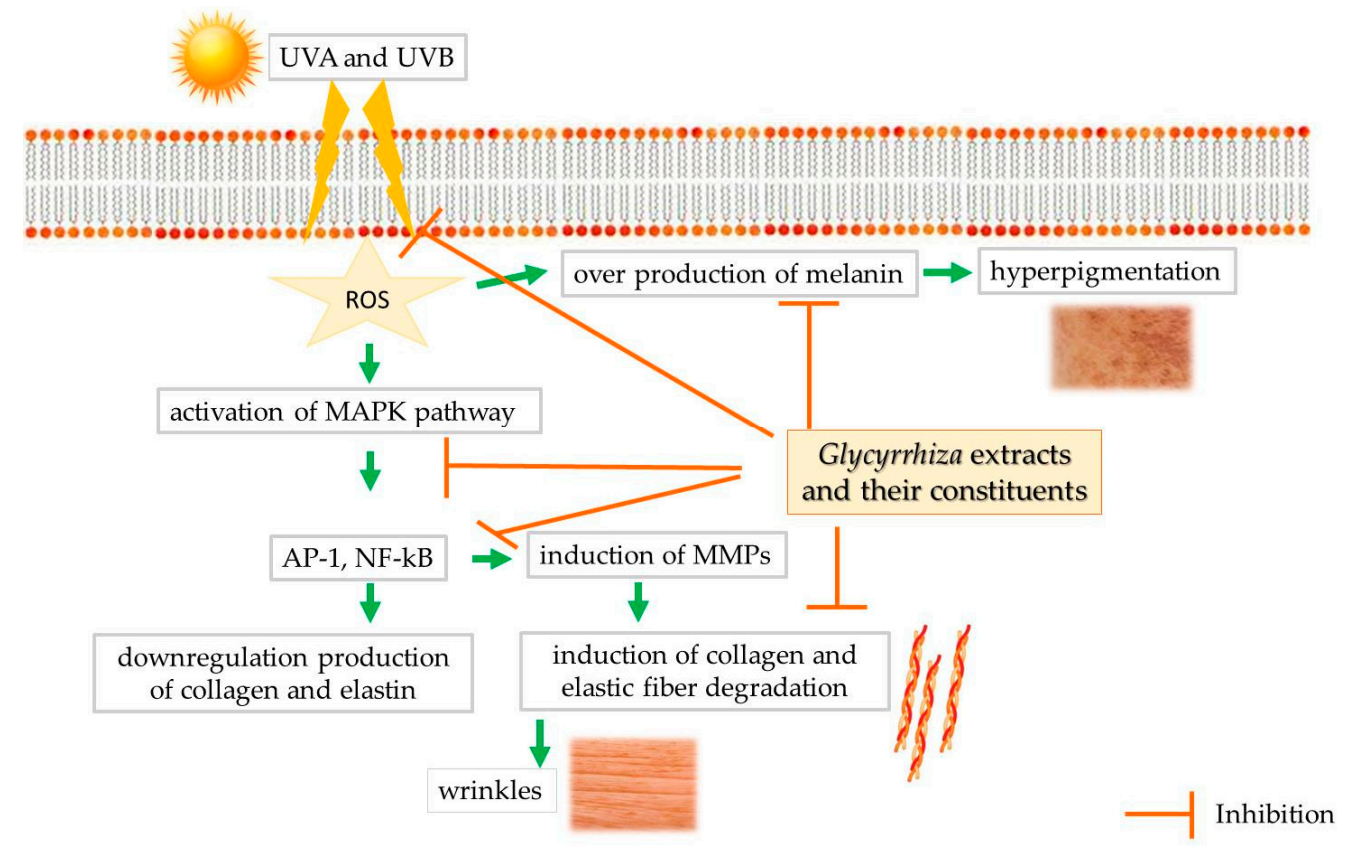

Figure 4. Prevention of photoaging by Glycyrrhiza root extracts and their constituents.

Ishi et al. reported different types of oil in water $(\mathrm{O} / \mathrm{W})$ herbal creams using herbal extracts such as Curcuma longa, with excellent potential for anti-aging, and G. glabra, known for the therapeutic effects in skin whitening, plus stearic acid and cetyl alcohol, and other excipients. The evaluation of formulations highlighted how they were safe to be used for the skin and could be used as skin lightening and anti-oxidant agents [50].

At the same time, other researchers evaluated the skin lightening capacity of G. glabra root extracts in cream preparation. In particular, Kirubakaran et al. highlighted the skinlightening properties of cream prepared using G. glabra root extracts and G. indica bark extracts and physical sun protecting agents such as titanium dioxide. Synergism between selected extracts generated the melanin inhibition effect through the cellular melanin inhibition pathway. Consequently, the preparation mentioned above could be used for skin-whitening for better skin aesthetics [33].

A herbal face cream, in which G. glabra was combined with other herbal extracts, showed multipurpose effects such as whitening, antiwrinkle, anti-aging, and sunscreen effect, due to a synergistic effect between all the extracts [51]. In addition to the extracts, the skin-whitening properties were also reported for the bioactive compounds glycyrrhisoflavone, kaempferol, glyasperin C, and glyasperin D [52,53].

\subsection{Antiwrinkle Activity}

Among the most frequent phenotypic manifestations of intrinsic and extrinsic aging is the onset of wrinkles at different depth levels, due to the progressive loss of structural integrity and physiological function of the skin [54]. The inevitable intrinsic skin aging is due to physiological aging characterized by the decline of collagen, elastin, and hyaluronic acid levels, leading to a loss of strength and flexibility in the skin, which results in visible wrinkles associated with the thickened epidermis, mottled discoloration, laxity, dullness, and roughness of the skin. Extrinsic skin aging is due to diverse determinants such as sun exposure, external pollutants, smoking, and diet [55].

Exposure of human skin to ROS (reactive oxygen species) through several factors, including UV, has been reported to enhance matrix metalloproteinases (MMPs) activity associated with a notable breakdown of collagen fibers. MMPs, in particular gelatinases (MMP-2 and -9) that cleave soluble type-IV and type-I collagen, represent the major enzymes responsible for the degradation of the extracellular matrix which contains diverse biomolecules including collagen and gelatin (Figure 4) [56]. 
Ryu et al. reported how 1,3-butylene glycol extract of G. uralensis reduced ROS production by inhibition of MMP-2 activity along with the consequent increase of collagen production. Furthermore, the results suggested the use of G. uralensis extract as a cosmetic ingredient with antiwrinkle and anti-oxidant effects [55]. Antiwrinkle activity by antioxidant mechanism has been proved for G. glabra extract at the dose of $150 \mathrm{mg} / \mathrm{kg} / \mathrm{day}$ [57]. Moreover, Ciganovic et al. highlighted for G. glabra extract, obtained by a green ultrasoundassisted extraction method using glycerol/water mixtures, a good anti-oxidant activity, tyrosinase, and elastase inhibitory activity as well as anti-inflammatory activity, leading to excellent anti-aging properties [58].

Prenylflavonoids dehydroglyasperin C, dehydroglyasperin D, and isoangustone A showed a superoxide scavenger activity as a mechanism to prevent wrinkles [59].

Moreover, eicosanyl caffeate and docosyl caffeate, two long-chain caffeoyl esters isolated by ethyl acetate extract of G. glabra roots displayed by a spectrophotometric assay a potent elastase inhibitory activity, an additional target to prevent aging and wrinkles formation [60], with $\mathrm{IC}_{50}$ values of $0.99 \mu \mathrm{g} / \mathrm{mL}$ and $1.4 \mu \mathrm{g} / \mathrm{mL}$, respectively [61].

\section{Photoprotective Activity}

Ultraviolet (UV) irradiation causes several areas of damage to the skin. Together with immune suppression, cancer, tanning, and sunburn, it provokes injuries called photoaging, consisting of connective tissue degradation [62] (Figure 4). UV-B rays are the most dangerous, producing physiological responses connected with oxidative stress, resulting in cell death at high dosage. On the other hand, minor UV-B irradiation induces oxidative stress and activates intracellular signal transduction pathways. Several anti-oxidants extracted from plants are involved in reduced incidence of photocarcinogenesis and photoaging, and, for these reasons, the relative extracts can be considered for their skin photoprotective effects [63].

\subsection{Anti-Photoaging Effects}

Photoaging is the macroscopic and microscopic modification caused by persistent sun exposure. Most effectors involved in skin photoaging are pro-inflammatory cytokines, ROS, and effector molecules like MMP-1. Their generation is controlled by NF-kappa B, produced due to UV exposition (Figure 4) [64].

Afnan et al. in 2012 evaluated the effect of glycyrrhizinic acid on UV-B photoaging induced by irradiation with a sub-toxic dose of UV-B $\left(10 \mathrm{mj} / \mathrm{cm}^{2}\right)$ of human dermal fibroblasts (HDFs) and its possible mechanism of action. The involvement of glycyrrhizinic acid on cell viability, matrix metalloproteinase 1 (MMP1), pro-collagen 1, cellular and nuclear morphology, cell cycle, intracellular ROS, caspase 3, and hyaluronidase inhibition assays was evaluated. The principal mechanism appeared to be connected with the block of MMP1 activation by modulating NF-kB signaling [65].

Based on the involvement of MMP in photoaging, a study published in 2017 by Xuan et al. assessed the anti-photoaging effects of dehydroglyasperin $C$ on MMPs levels in $\mathrm{HaCaT}$ human keratinocytes and tried to elucidate the biological mechanism. Dehydroglyasperin C noticeably repressed UV-B-mediated expression of collagenase (MMP-1) and gelatinase (MMP-9) by inhibiting ROS generation. Dehydroglyasperin C treatment also decreased the UV-B irradiation-mediated activation of mitogen-activated protein kinase (MAPK), c-Jun phosphorylation, and c-fos expression. In addition, the down-regulation of UV-B-induced c-Jun phosphorylation caused by dehydroglyasperin C treatment was more intense than the down-regulation of c-fos expression. In conclusion, it appeared that dehydroglyasperin C may work as a potential anti-photoaging agent by inhibiting UV-Bmediated MMPs expression via suppression of MAPK and AP-1 signaling (Figure 4) [66].

Other phytochemicals extracted from Glycyrrhiza spp. appeared to be involved against photoaging caused by UV-B. Puri and coworkers in 2017 published a paper on the development of microemulsions of dibenzoylmethane for the treatment of UV-induced photoaging [67]. Dibenzoylmethane exerted sunscreen activity, preventing the damage caused by 
UV rays. It acted as a UV-A screen that prevented the penetration of the UV radiation in the vital cells and blocked the overproduction of ROS. The authors evaluated in vivo photoprotection in a mice model of UV-radiation-induced photodamage [67].

Another compound evaluated for its contribution to reduce photoaging was licoricidin. Its effects were assessed on photoaging of human dermal fibroblasts (HDFs) submitted to irradiation with UV-A. Licoricidin blocked UV-A-induced photoaging acting as ROS scavenger. This activity is connected with the modulation of MMP-1 [68].

\subsection{Photoprotective Effect against $U V-B$ and Visible Radiation}

In addition to the UV protection, Mann et al. in 2020 investigated ROS production induced by visible radiation and the mechanism of photoprotection of licochalcone A. The mechanism appeared to involve the stimulation of Nrf2/ARE signaling pathway, as preliminarily presented in a previous study $[69,70]$. Randomized clinical trials were carried out to assess the anti-irritative potential of formulation with licochalcone A on UV-induced erythema formation. The formulation caused a highly noteworthy reduction in UV-induced erythema tests, resulting in a powerful inhibition of pro-inflammatory in vitro reactions, including UV-B-induced PGE2 release by keratinocytes [71]. The activity of licochalcone A on UV-B-induced erythema was also tested and confirmed on patients with rosacea and red facial skin, for whom skin tolerance, efficacy, and quality of life were evaluated [72].

Melatonin (N-acetyl-5-methoxytryptamine) is synthesized and secreted by the pineal gland in vertebrates. The occurrence of melatonin in roots of $G$. uralensis and the response of this plant to different light (red, blue, and white) and UV-B irradiation (280-315 nm) for the synthesis of melatonin were investigated. Production of melatonin in G. uralensis plants is connected with protection against oxidative damage initiated as a response to UV irradiation [73].

In a more specific cosmetic approach, a moisturizing cream (oil in water)-based formulation containing an extract of Beta-vulgaris $(1 \%)$ and an extract of G. glabra $(1 \%)$ was developed to provide a UV-A/UV-B protective moisture to be used for post-laser therapy. In addition, this cream facilitated re-pigmentation by stimulating melanocytic proliferation and removing stubborn scars and wrinkles [74].

\subsection{Anti-Oxidant Effects}

Anti-oxidant activity of the functional ingredients in cosmetic products is of great importance. Functional cosmeceutical ingredients with anti-oxidant activity may have a more active role in such products [31]. They also offer protection against oxidative damage of skin macromolecules associated with the effects of free radicals and UV radiation on the skin [58,75]. The anti-oxidant activity of G. glabra is one of the reasons for its uses in cosmetics and generally is connected with other activities like photoprotection. The phenolic content is probably responsible for the observed anti-oxidant activity attributed to flavonoids, isoflavones, methylated isoflavones, and chalcones [76,77].

The anti-oxidant potential of glabridin was reviewed in a specific paper on the potential of glabridin and its biological properties [17].

Licochalcones B and D showed a strong scavenging activity in the DPPH assay and the ability to inhibit microsomal lipid peroxidation. These phenolic compounds appeared to be effective in protecting biological systems against oxidative stress, being able to inhibit skin damage $[78,79]$.

The anti-oxidant potential of licorice to be used for preserving cosmetic formulations was evaluated. The extract was tested for anti-oxidative activity in comparison with antioxidants (sodium metabisulfite and BHT) at $0.1 \%, 0.5 \%, 1.0 \%$, and $2.0 \% w t . / w t$. in a cream formulation with $2 \% w t . / w t$. of hydroquinone. The results suggested the use of licorice extracts at 0.5 and $1.0 \%$ as an effective natural anti-oxidant able to preserve formulations that are susceptible to oxidation [80].

On the other hand, it appears that not only phenolic compounds are involved in the anti-oxidant effect of licorice extracts. In addition saponins from licorice showed 
anti-oxidant activity, suggesting their possible use in body wash cosmetic products [81]. Polysaccharides isolated from three varieties of G. glabra also exhibited anti-oxidant activity [82]. Due to their good anti-oxidant properties, licorice polysaccharides are suggested as an additive to delay skin aging and prevent the formation of chloasma in cosmetics [6].

Sometimes Glycyrrhiza extracts were used in polyherbal cosmetic formulations, and the anti-oxidant effects were generally improved for a synergistic effect [83].

\section{Hair Care}

Hair, a part of the body connected with physical appeal, is recognized as a health indicator. Hair treatments and cosmetic products for hair care are continuously under research. The treatment of hair and scalp mainly involves the use of shampoo for cleansing; the shampoo is considered not only a cosmetic product having a purifying purpose, but also a formulation responsible for maintaining the health and beauty of the hair. Herbal shampoos can be used functionally, and among the different herbal extracts to be used for this purpose, an interesting position is occupied by licorice extracts as reported in a recent review [84].

\subsection{Hair Growth}

Licorice extracts in hair care formulation present an interesting activity to promote hair growth. A recent investigation evaluated the safety, stability, and hair growth activity of an ethanol extract of licorice (G. glabra). The hair tonic solutions containing this extract showed hair growth activity similar to that of the positive control (minoxidil), good physical and chemical stability, and safe topical use [85].

The beneficial effects of an oriental herbal supplement containing G. uralensis in addition to Glycine max, and Thuja orientalis were assessed on women's hair numbers, hair diameter, scalp moisture and sebum, and scalp conditions, finding a real benefit in improving hair and scalp conditions [68]. In addition, other formulations containing licorice showed beneficial effects as a remedy for hair fall $[86,87]$.

The effect on the promotion of hair growth was previously confirmed by a study on cells, for a mixture composed of extracts of G. uralensis, Angelica gigas, Acoruscalamus, Cnidium officinale, Panax ginseng, Camellia sinensis, Salvia miltiorrhiza, Zanthoxylum schinifolium, Carthamustinctorius, Prunus persica, and Scrophularia buergeriana. The study was performed in human hair dermal papilla cells and C57BL/6J cells of mice. The mixture significantly increased the proliferation of human hair dermal papilla cells in a dose- and time-dependent manner [88].

\subsection{General Hair Care and Dandruff}

In the review published in 2020 by Shivakant, the functional effects on scalp care were reported for a scalp tonic containing licorice [84]. Dandruff is a common scalp problem connected with flaky and inflamed skin. In a clinical trial 102 subjects (male 56 and 46 female) with moderate to very strong dandruff affliction used a combination of piroctone, olamine, and licochalcone A. In this study, a cytokine analysis was performed, and the results proved a significant decrease in pro-inflammatory dandruff markers after treatment with the tested products. Moreover, the anti-fungal activity of test products was detected, revealing a significant reduction of Malassezia colony-forming units after treatment with the anti-dandruff shampoo. The benefit exerted by the combination was primarily based on the known anti-inflammatory effect of licochalcone A [89]. In a recent investigation, silver nanoparticles containing G. glabra extract showed antimicrobial effects against dandruff caused by pathogens. Protein leakage analysis revealed that this formulation disturbed the solidity of pathogens' membrane [90].

\section{Anti-Acne Potential}

Acne vulgaris is a widespread skin syndrome, which is also a chronic inflammatory disease of pilosebaceous unit that includes the increase of sebum production by sebaceous 
glands and abnormal desquamation of hair follicles that happens in reaction to increasing of androgen levels with the beginning of puberty. Natural remedies are often more tolerable and related to minor side effects than synthetic ones [91,92].

\section{Anti-Acne Activity}

G. glabra seems to be an interesting remedy against acne. The anti-acne therapeutic effects of oriental herb extracts among which G. glabra were investigated in terms of antichemotactic effects on polymorphonuclear leucocytes, antilipogenic, and antibacterial effects against Propionibacterium acnes. G. glabra showed remarkable antibacterial activity against $P$. acnes with a negligible induction of resistance compared to marked development of resistance in bacteria treated with erythromycin [93].

In an overview of the plants used for skin diseases, the anti-acne effects of G. glabra were reviewed additionally to the activity of the plant extracts on atopic dermatitis [94].

The anti-acne activity of licorice can be the result of multifactorial effects. The antiacne activity was connected with moisturizing action for several herbal extracts including G. glabra [95], but the most probable mechanism is the antimicrobial action against acne bacteria [96,97], although the anti-androgenic activity was proposed as a mechanism of action connected with the anti-acne final effect [98]. To clarify the plural activities of licorice on dermatological disorders, a pharmacological study on mice was conducted [99]. In this study licorice significantly increased epidermal thicknesses as compared to control animals. The volume of the sebaceous gland and the thickness were significantly increased in the disease model compared to the control animals and resulted reduced by licorice extract.

It is possible to find several papers reporting poli-herbal formulations in literature, including Glycyrrhiza with synergistic anti-acne activity. The most recent was proposed in 2020 by Keshri and Khare [91], but other synergistic formulations were proposed before $[96,97,100-103]$.

Few studies are reported in the literature about the molecules involved in this activity. The anti-acne activity of licochocalcone A resulted in efficient suppression of the NLPR3 inflammasome [104]. Activation of the nucleotide-binding domain, leucine-rich-containing family, pyrin domain-containing-3 (NLRP-3) inflammasome by P. acnes is a critical point for inducing inflammation and aggravating the development of acne lesions [104].

Controlled clinical studies on botanical extracts used in dermatology were reviewed in 2010 by Reuter and coworkers [94], focusing on clinical trials with botanicals in treating acne, inflammatory skin diseases, skin infections, UV-induced skin damage, skin cancer, alopecia, vitiligo, and wounds. In acne therapy, Glycyrrhiza may have the potential to become a standard treatment [94].

\section{Conclusions}

In the last years, there has been a growing interest in using extracts and natural compounds from plants instead of synthetic compounds in the cosmetic field. The application of Glycyrrhiza extracts and natural compounds from licorice, mainly flavonoid compounds, for their skin anti-aging, photoprotective activity, hair care, and anti-acne activity, is more and more diffused.

Root extracts are mainly used in cosmetics for the whitening effects. A commercial formulation containing glabridin is claimed to have a 1000 times stronger whitening effect than vitamin C. Due to this property, glabridin is known as "whitening gold" and is quite popular as a whitening ingredient in internationally standard cosmetics [12].

This review has shown a wide array of activities of Glycyrrhiza extracts and their constituents potentially valuable for cosmetic and dermatologic products.

Glycyrrhiza extracts and flavonoid compounds from licorice exert their whitening effect as inhibitors of tyrosinase, the central enzymatic system of melanogenesis, become one of the most important targets for the control of hyperpigmentary disorders (Figure 3). This review confirmed that despite the diversity of natural inhibitors, many tyrosinase 
inhibitors belong to the phenolic class [35], thus along with the most cited glabridin, other flavonoids from licorice may contribute to skin depigmentation.

Interestingly, these molecules are mainly represented by isoflavonoids characterized by the occurrence of prenyl moieties on A ring or B ring. Along with the effects on skin depigmentation, licorice extract-based formulations may be of value in innovative dermal and cosmetic products as they counteract oxidative stress damage, maintaining the skin homeostasis due to their high antioxidant content. In this review it is evident that several investigations were carried out on G. glabra and G. uralensis, but very few reports account for G. inflata. Therefore, based on the chemistry of this latter characterized by the presence not only of licochalcone A, further researches have to be performed to assess its cosmeceutical value.

As evident from literature, licochalcone $\mathrm{A}$, glabridin, and dehydroglyasperin $\mathrm{C}$ are licorice most investigated flavonoids, suggesting further development and application in cosmetic industries in the future (Figure 5). Other constituents have also shown cosmeceutical properties but further investigations have to be performed to meet industrial purposes. The first goal could be the selection of Glycyrrhiza species taking into account the occurrence of the metabolites of interest. Additionally, the choice of the extraction and purification methods is crucial to obtain a higher amount of the selected constituents. Regarding this topic, the research is increasingly oriented towards greener alternatives, many of which are still to be investigated.

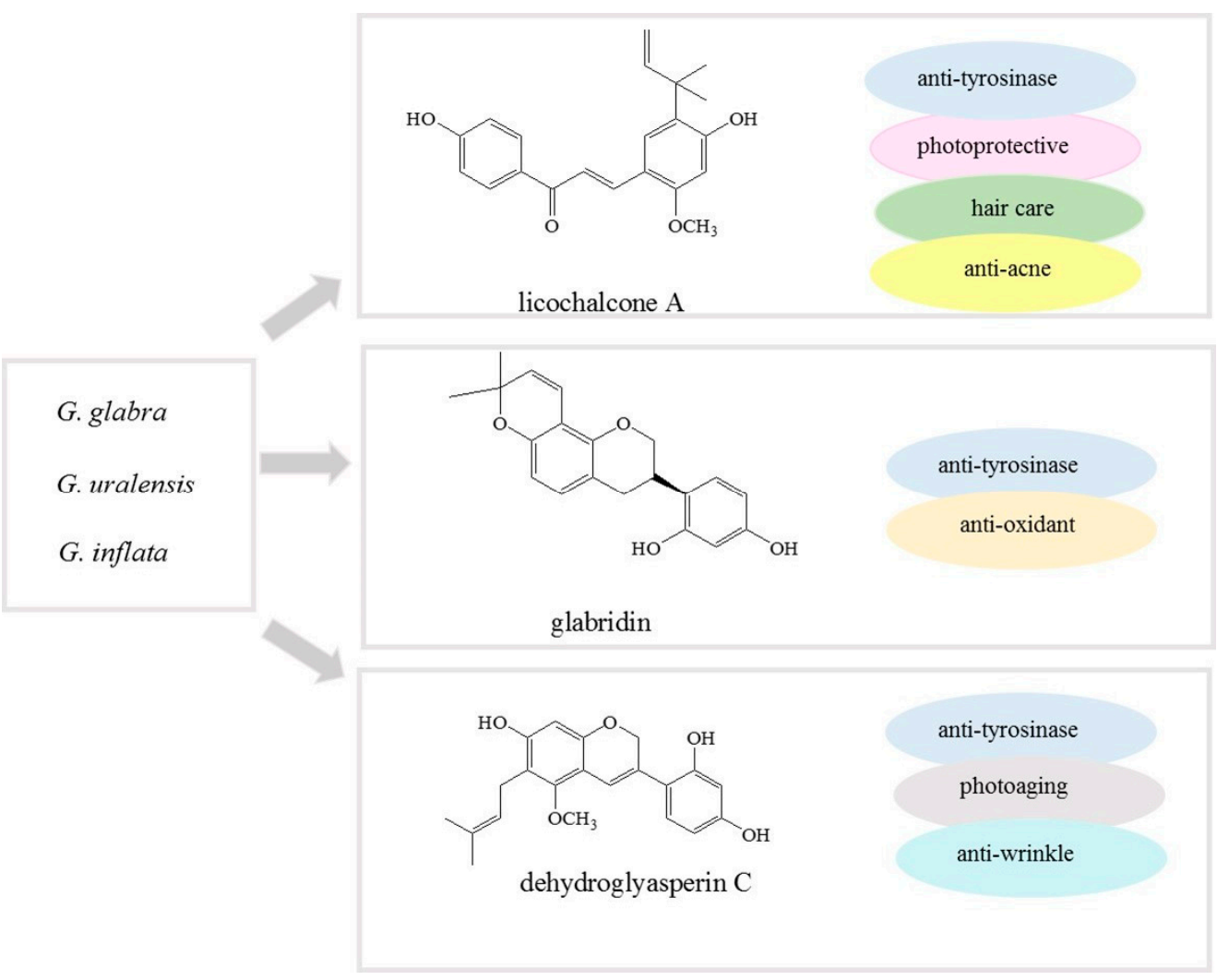

Figure 5. Cosmeceutical effects of the most studied bioactive compounds from Glycyrrhiza spp.

A recent review describes the toxicity effects of licorice and glycyrrhizin in acute, subacute, sub-chronic, and chronic states, highlighting their moderate toxicity and the need to be used with caution during pregnancy. However, their toxicity was mainly evaluated after oral administration and intraperitoneal, subcutaneous, intravenous, and intramuscular injection [105]. Therefore, additional investigations should be carried out to assess the toxicity of topical administration. 


\begin{abstract}
Author Contributions: A.C., M.M., P.M. and S.P. have contributed equally to the elaboration of this work. All authors have read and agreed to the published version of the manuscript.
\end{abstract}

Funding: This research received no external funding.

Institutional Review Board Statement: Not applicable.

Informed Consent Statement: Not applicable.

Data Availability Statement: This work does not present any associated data.

Conflicts of Interest: The authors declare no conflict of interest.

\title{
References
}

1. Gao, X.H.; Zhang, L.; Wei, H.; Chen, H.D. Efficacy and safety of innovative cosmeceuticals. Clin. Dermatol. 2008, 26, 367-374. [CrossRef] [PubMed]

2. Hoang, H.T.; Moon, J.-Y.; Lee, Y.-C. Natural Antioxidants from Plant Extracts in Skincare Cosmetics: Recent Applications, Challenges and Perspectives. Cosmetics 2021, 8, 106. [CrossRef]

3. Batiha, G.E.; Beshbishy, A.M.; El-Mleeh, A.; Abdel-Daim, M.M.; Devkota, H.P. Traditional Uses, Bioactive Chemical Constituents, and Pharmacological and Toxicological Activities of Glycyrrhiza glabra L. (Fabaceae). Biomolecules 2020, 10, 352. [CrossRef]

4. Pastorino, G.; Cornara, L.; Soares, S.; Rodrigues, F.; Oliveira, M. Liquorice (Glycyrrhiza glabra): A phytochemical and pharmacological review. Phytother. Res. 2018, 32, 2323-2339. [CrossRef]

5. Cheng, M.; Zhang, J.; Yang, L.; Shen, S.; Li, P.; Yao, S.; Qu, H.; Li, J.; Yao, C.; Wei, W.; et al. Recent advances in chemical analysis of licorice (Gan-Cao). Fitoterapia 2021, 149, 104803. [CrossRef]

6. Simayi, Z.; Rozi, P.; Yang, X.J.; Ababaikeri, G.; Maimaitituoheti, W.; Bao, X.W.; Ma, S.J.; Askar, G.; Yadikar, N. Isolation, structural characterization, biological activity, and application of Glycyrrhiza polysaccharides: Systematic review. Int. J. Biol. Macromol. 2021, 183, 387-398. [CrossRef]

7. Shakeri, A.; Masullo, M.; D’Urso, G.; Iranshahi, M.; Montoro, P.; Pizza, C.; Piacente, S. In depth chemical investigation of Glycyrrhiza triphylla Fisch roots guided by a preliminary HPLC-ESIMS ${ }^{2}$ profiling. Food Chem. 2018, 248, 128-136. [CrossRef] [PubMed]

8. Kirmizibekmez, H.; Uysal, G.B.; Masullo, M.; Demirci, F.; Bagci, Y.; Kan, Y.; Piacente, S. Prenylated polyphenolic compounds from Glycyrrhiza iconica and their antimicrobial and antioxidant activities. Fitoterapia 2015, 103, 289-293. [CrossRef]

9. Fu, Y.; Chen, J.; Li, Y.J.; Zheng, Y.F.; Li, P. Antioxidant and anti-inflammatory activities of six flavonoids separated from licorice. Food Chem. 2013, 141, 1063-1071. [CrossRef] [PubMed]

10. Vanitha, M.; Soundhari, C. Isolation and characterisation of mushroom tyrosinase and screening of herbal extracts for anti tyrosinase activity. Int. J. Chem. Tech. Res. 2017, 10, 1156-1167.

11. Wang, C.; Chen, L.; Xu, C.; Shi, J.; Chen, S.; Tan, M.; Chen, J.; Zou, L.; Chen, C.; Liu, Z.; et al. A Comprehensive Review for Phytochemical, Pharmacological, and Biosynthesis Studies on Glycyrrhiza spp. Am. J. Chin. Med. 2020, 48, 17-45. [CrossRef] [PubMed]

12. Husain, I.; Bala, K.; Khan, I.A.; Khan, S.I. A review on phytochemicals, pharmacological activities, drug interactions, and associated toxicities of licorice (Glycyrrhiza sp.). Food Front. 2021, 2, 449-485. [CrossRef]

13. Li, F.; Liu, B.; Li, T.; Wu, Q.; Xu, Z.; Gu, Y.; Li, W.; Wang, P.; Ma, T.; Lei, H. Review of Constituents and Biological Activities of Triterpene Saponins from Glycyrrhizae Radix et Rhizoma and Its Solubilization Characteristics. Molecules 2020, 25, 3904. [CrossRef]

14. Karkanis, A.; Martins, N.; Petropoulos, S.A.; Ferreira, I.C.F.R. Phytochemical composition, health effects, and crop management of liquorice (Glycyrrhiza glabra L.): A medicinal plant. Food Rev. Int. 2018, 34, 182-203. [CrossRef]

15. Pandey, P.; Singh, D.C.; Pradhan, S.; Semwal, D.K. Comparative pharmacognostical \& phytochemical study of Chakramard seed \& Gomutra bhavit Chakramard seed. Eur. J. Biomed. Pharm. Sci. 2020, 7, 401-408.

16. Sharma, V.; Katiyar, A.; Agrawal, R.C. Glycyrrhiza glabra: Chemistry and Pharmacological Activity. Sweeten. Pharmacol. Biotechnol. Appl. 2017, 87-100. [CrossRef]

17. Simmler, C.; Pauli, G.F.; Chen, S.-N. Phytochemistry and biological properties of glabridin. Fitoterapia 2013, 90, 160-184. [CrossRef]

18. Masullo, M.; Pizza, C.; Piacente, S. Oleanane derivatives for pharmaceutical use: A patent review (2000-2016). Expert. Opin. Ther. Pat. 2017, 27, 237-255. [CrossRef] [PubMed]

19. Montoro, P.; Maldini, M.; Russo, M.; Postorino, S.; Piacente, S.; Pizza, C. Metabolic profiling of roots of liquorice (Glycyrrhiza glabra) from different geographical areas by ESI/MS/MS and determination of major metabolites by LC-ESI/MS and LC-ESI/MS/MS. J. Pharm. Biomed. 2011, 54, 535-544. [CrossRef] [PubMed]

20. Song, W.; Qiao, X.; Chen, K.; Wang, Y.; Ji, S.; Feng, J.; Li, K.; Lin, Y.; Ye, M. Biosynthesis-Based Quantitative Analysis of 151 Secondary Metabolites of Licorice To Differentiate Medicinal Glycyrrhiza Species and Their Hybrids. Anal. Chem. 2017, 89, 3146-3153. [CrossRef]

21. Xiang, C.; Qiao, X.; Ye, M.; Guo, D.A. Classification and distribution analysis of components in Glycyrrhiza using licorice compounds database. Acta Pharm. Sin. 2012, 47, 1023-1030. 
22. Jiang, Z.Z.; Wang, Y.F.; Zheng, Y.F.; Yang, J.; Zhang, L. Ultra high performance liquid chromatography coupled with triple quadrupole mass spectrometry and chemometric analysis of licorice based on the simultaneous determination of saponins and flavonoids. J. Sep. Sci. 2016, 39, 2928-2940. [CrossRef]

23. Baba, M.; Fukuda, E.; Uesawa, Y.; Kai, H.; Matsuno, K.; Okada, Y. Application of Mixture Analysis to Crude Materials from Natural Resources (V) [1]: Discrimination of Glycyrrhiza uralensis and G. glabra by El mass spectrometry. Nat. Prod. Commun. 2017, 12, 27-29. [CrossRef] [PubMed]

24. Farag, M.A.; Porzel, A.; Wessjohann, L.A. Comparative metabolite profiling and fingerprinting of medicinal licorice roots using a multiplex approach of GC-MS, LC-MS and 1D NMR techniques. Phytochemistry 2012, 76, 60-72. [CrossRef]

25. Simmler, C.; Anderson, J.R.; Gauthier, L.; Lankin, D.C.; McAlpine, J.B.; Chen, S.N.; Pauli, G.F. Metabolite Profiling and Classification of DNA-Authenticated Licorice Botanicals. J. Nat. Prod. 2015, 78, 2007-2022. [CrossRef] [PubMed]

26. Suzuki, R.; Nakano, F.; Ohno, H.; Murakami, T.; Okada, Y.; Shirataki, Y. Distinguishing Glycyrrhiza species using NMR-based Metabolomics. Nat. Prod. Comm. 2018, 13, 71-73. [CrossRef]

27. Vijayalakshmi, U.; Shourie, A. Evaluation of different methods for the extraction of antioxidant phenolic compounds from Glycyrrhiza glabra roots. World J. Pharm. Res. 2015, 4, 1524-1537.

28. Tian, M.; Yan, H.; Row, K.H. Extraction of Glycyrrhizic Acid and Glabridin from Licorice. Int. J. Mol. Sci. 2008, 9, 571-577. [CrossRef]

29. Luo, Z.; Guo, Z.; Xiao, T.; Liu, H.; Su, G.; Zhao, Y. Enrichment of total flavones and licochalcone A from licorice residues and its hypoglycemic activity. J. Chromatogr. B 2019, 1114-1115, 134-145. [CrossRef]

30. Campa, M.; Baron, E. Anti-aging Effects of Select Botanicals: Scientific Evidence and Current Trends. Cosmetics 2018, 5, 54 [CrossRef]

31. Thiviya, P.; Gamage, A.; Piumali, D.; Merah, O.; Madhujith, T. Apiaceae as an Important Source of Antioxidants and Their Applications. Cosmetics 2021, 8, 111. [CrossRef]

32. Mahendra, C.K.; Tan, L.T.H.; Mahendra, C.K.; Ser, H.-L.; Pusparajah, P.; Htar, T.T.; Chuah, L.-H.; Yap, W.H.; Tang, S.Y.; Ming, L.C.; et al. The Potential of Sky Fruit as an Anti-Aging and Wound Healing Cosmeceutical Agent. Cosmetics 2021, 8, 79. [CrossRef]

33. Kirubakaran, N.; Thiyagarajan; Mahendra, C.; Varma, S.; Kumar, V.; Tripathi, V.; Babu. Design and development of emulsionbased clear complexion skin whitening cream using Glycyrrhiza glabra (Licorice) root extract and Vateria indica (white dammar) bark extract by skin melanin inhibitory pathway. Int. J. Pharm. Sci. Res. 2017, 8, 1210-1219. [CrossRef]

34. Ruchi, G.; Rajiv, S.; Archana, P.; Yashu, C.; Neelesh, M. Review on antityrosinase activity of some Indian medicinal plants and their phytoconstituents. J. Drug Deliv. Ther. 2020, 10, 199-204. [CrossRef]

35. Panzella, L.; Napolitano, A. Natural and Bioinspired Phenolic Compounds as Tyrosinase Inhibitors for the Treatment of Skin Hyperpigmentation: Recent Advances. Cosmetics 2019, 6, 57. [CrossRef]

36. Opperman, L.; De Kock, M.; Klaasen, J.; Rahiman, F. Tyrosinase and Melanogenesis Inhibition by Indigenous African Plants: A Review. Cosmetics 2020, 7, 60. [CrossRef]

37. Uto, T.; Ohta, T.; Yamashita, A.; Fujii, S.; Shoyama, Y. Liquiritin and liquiritigenin induce melanogenesis via enhancement of p38 and PKA signaling pathways. Medicines 2019, 6, 68. [CrossRef] [PubMed]

38. Chaita, E.; Lambrinidis, G.; Cheimonidi, C.; Agalou, A.; Beis, D.; Trougakos, I.; Mikros, E.; Skaltsounis, A.-L.; Aligiannis, N. Anti-melanogenic properties of Greek plants. A novel depigmenting agent from Morus alba wood. Molecules 2017, $22,514$. [CrossRef]

39. Zhu, W.; Gao, J. The Use of Botanical Extracts as Topical Skin-Lightening Agents for the Improvement of Skin Pigmentation Disorders. J. Investig. Dermatol. Symp. Proc. 2008, 13, 20-24. [CrossRef]

40. Chen, J.; Yu, X.; Huang, Y. Inhibitory mechanisms of glabridin on tyrosinase. Spectrochim. Acta Part A 2016, 168, 111-117. [CrossRef]

41. Hespeler, D.; Kaltenbach, J.; Pyo, S.M. Glabridin smartPearls-Silica selection, production, amorphous stability and enhanced solubility. Int. J. Pharm. 2019, 561, 228-235. [CrossRef]

42. Nerya, O.; Vaya, J.; Musa, R.; Izrael, S.; Ben-Arie, R.; Tamir, S. Glabrene and isoliquiritigenin as tyrosinase inhibitors from licorice roots. J. Agric. Food Chem. 2003, 51, 1201-1207. [CrossRef]

43. Dong, Y.; Zhao, M.; Zhao, T.; Feng, M.; Chen, H.; Zhuang, M.; Lin, L. Bioactive profiles, antioxidant activities, nitrite scavenging capacities and protective effects on $\mathrm{H}_{2} \mathrm{O}_{2}$-injured PC12 cells of Glycyrrhiza Glabra L. leaf and root extracts. Molecules 2014, 19, 9101-9113. [CrossRef]

44. Lin, Y.; Kuang, Y.; Li, K.; Wang, S.; Song, W.; Qiao, X.; Sabir, G.; Ye, M. Screening for bioactive natural products from a 67-compound library of Glycyrrhiza inflata. Bioorg. Med. Chem. 2017, 25, 3706-3713. [CrossRef]

45. Liu, L.; Shi, S.; Chen, X.; Peng, M. Analysis of tyrosinase binders from Glycyrrhiza uralensis root: Evaluation and comparison of tyrosinase immobilized magnetic fishing-HPLC and reverse ultrafiltration-HPLC. J. Chromatogr. B Anal. Technol. Biomed. Life Sci. 2013, 932, 19-25. [CrossRef]

46. Lim, J.W.; Ha, J.H.; Jeong, Y.J.; Park, S.N. Anti-melanogenesis effect of dehydroglyasperin C through the downregulation of MITF via the reduction of intracellular cAMP and acceleration of ERK activation in B16F1 melanoma cells. Pharmacol. Rep. 2018, 70, 930-935. [CrossRef]

47. Maddaleno, A.S.; Camargo, J.; Mitjans, M.; Vinardell, M.P. Melanogenesis and Melasma Treatment. Cosmetics $2021,8,82$. [CrossRef] 
48. Amer, M.; Metwalli, M. Topical liquiritin improves melasma. Int. J. Dermatol. 2000, 39, 299-301. [CrossRef] [PubMed]

49. Alexis, A.F.; Blackcloud, P. Natural ingredients for darker skin types: Growing options for hyperpigmentation. J. Drugs Dermatol. 2013, 12, s123-s127. [PubMed]

50. Ishi, H.S.; Pawar, S.P.; Patil, S.T. A research: Design, development and evaluation of herbal skin lightening cream. World J. Pharm. Pharm. Sci. 2017, 6, 992-1003. [CrossRef]

51. Parashar, B.; Sharma, P.; Kabra, A. Formulation and evaluation of polyherbal face cream. Int. Pharm. Sci. 2013, 3, 63-68.

52. Kim, H.J.; Seo, S.H.; Lee, B.-g.; Lee, Y.S. Identification of tyrosinase inhibitors from Glycyrrhiza uralensis. Planta Med. 2005, 71, 785-787. [CrossRef]

53. Ji, S.; Li, Z.; Song, W.; Wang, Y.; Liang, W.; Li, K.; Tang, S.; Wang, Q.; Qiao, X.; Zhou, D.; et al. Bioactive Constituents of Glycyrrhiza uralensis (Licorice): Discovery of the Effective Components of a Traditional Herbal Medicine. J. Nat. Prod. 2016, 79, 281-292. [CrossRef]

54. Rizzi, V.; Gubitosa, J.; Fini, P.; Cosma, P. Neurocosmetics in Skincare-The Fascinating World of Skin-Brain Connection: A Review to Explore Ingredients, Commercial Products for Skin Aging, and Cosmetic Regulation. Cosmetics 2021, 8, 66. [CrossRef]

55. Ryu, H.W.; Cho, J.K.; Curtis-Long, M.J.; Yuk, H.J.; Kim, Y.S.; Jung, S.; Kim, Y.S.; Lee, B.W.; Park, K.H. $\alpha$-Glucosidase inhibition and antihyperglycemic activity of prenylated xanthones from Garcinia mangostana. Phytochemistry 2011, 72, 2148-2154. [CrossRef]

56. Pittayapruek, P.; Meephansan, J.; Prapapan, O.; Komine, M.; Ohtsuki, M. Role of Matrix Metalloproteinases in Photoaging and Photocarcinogenesis. Int. J. Mol. Sci. 2016, 17, 868. [CrossRef]

57. Hooda, R. Antiwrinkle herbal drugs-An update. J. Pharmacogn. Phytochem. 2015, 4, 277-281.

58. Ciganovic, P.; Jakimiuk, K.; Tomczyk, M.; Koncic, M.Z. Glycerolic licorice extracts as active cosmeceutical ingredients: Extraction optimization, chemical characterization, and biological activity. Antioxidants 2019, 8, 445. [CrossRef]

59. Chakraborty, A.; Sahoo, M.; Roy, S.D.; Dasgupta, R.K. Anti-ageing natural herbs: A systemic review. Indian Res. J. Pharm. Sci. 2018, 5, 1589-1598. [CrossRef]

60. Jiratchayamaethasakul, C.; Ding, Y.; Hwang, O.; Im, S.-T.; Jang, Y.; Myung, S.-W.; Lee, J.M.; Kim, H.-S.; Ko, S.-C.; Lee, S.-H In vitro screening of elastase, collagenase, hyaluronidase, and tyrosinase inhibitory and antioxidant activities of 22 halophyte plant extracts for novel cosmeceuticals. Fish. Aquat. Sci. 2020, 23, 6. [CrossRef]

61. Dey, S.; Deepak, M.; Setty, M.; D'Souza, P.; Agarwal, A.; Sangli, G.K. Bioactive caffeic acid esters from Glycyrrhiza glabra. Nat. Prod. Res. 2009, 23, 1657-1663. [CrossRef]

62. Offord, E.A.; Gautier, J.-C.; Avanti, O.; Scaletta, C.; Runge, F.; Kramer, K.; Applegate, L.A. Photoprotective potential of lycopene, $\beta$-carotene, vitamin E, vitamin $C$ and carnosic acid in UVA-irradiated human skin fibroblasts. Free Radical Biol. Med. 2002, 32, 1293-1303. [CrossRef]

63. F'Guyer, S.; Afaq, F.; Mukhtar, H. Photochemoprevention of skin cancer by botanical agents. Photodermatol. Photoimmunol. Photomed. 2003, 19, 56-72. [CrossRef] [PubMed]

64. Tanaka, K.; Hasegawa, J.; Asamitsu, K.; Okamoto, T. Prevention of the ultraviolet B-mediated skin photoaging by a nuclear factor кB inhibitor, parthenolide. J. Pharmacol. Exp. Ther. 2005, 315, 624-630. [CrossRef]

65. Afnan, Q.; Adil, M.D.; Nissar-Ul, A.; Rafiq, A.R.; Amir, H.F.; Kaiser, P.; Gupta, V.K.; Vishwakarma, R.; Tasduq, S.A. Glycyrrhizic acid (GA), a triterpenoid saponin glycoside alleviates ultraviolet-B irradiation-induced photoaging in human dermal fibroblasts. Phytomedicine 2012, 19, 658-664. [CrossRef] [PubMed]

66. Xuan, S.H.; Park, Y.M.; Ha, J.H.; Jeong, Y.J.; Park, S.N. The effect of dehydroglyasperin C on UVB-mediated MMPs expression in human HaCaT cells. Pharmacol. Rep. 2017, 69, 1224-1231. [CrossRef]

67. Puri, A.; Kaur, A.; Raza, K.; Goindi, S.; Katare, O.P. Development and evaluation of topical microemulsion of dibenzoylmethane for treatment of UV induced photoaging. J. Drug Delivery Sci. Technol. 2017, 37, 1-12. [CrossRef]

68. Kim, S.H.; Jeon, H.Y.; Kim, S.K.; Lee, H.K.; Kim, B.J. The beneficial effects of an oriental herbal complex supplement on women's hair and scalp conditions: A 24-week, randomized, double-blind, placebo-controlled study. J. Food Nutr. Res. 2017, 5, 337-341. [CrossRef]

69. Mann, T.; Eggers, K.; Rippke, F.; Tesch, M.; Buerger, A.; Darvin, M.E.; Schanzer, S.; Meinke, M.C.; Lademann, J.; Kolbe, L. High-energy visible light at ambient doses and intensities induces oxidative stress of skin-Protective effects of the antioxidant and Nrf2 inducer Licochalcone A in vitro and in vivo. Photodermatol. Photoimmunol. Photomed. 2020, 36, 135-144. [CrossRef]

70. Liu, J.; Luo, L.; Zhang, H.; Jia, B.; Lu, J.; Li, P.; Chen, J. Rapid screening for novel antioxidants in Glycyrrhiza inflata using high-resolution peak fractionation. J. Funct. Foods 2015, 16, 40-49. [CrossRef]

71. Kolbe, L.; Immeyer, J.; Batzer, J.; Wensorra, U.; tom Dieck, K.; Mundt, C.; Wolber, R.; Staeb, F.; Schoenrock, U.; Ceilley, R.I.; et al. Anti-inflammatory efficacy of Licochalcone A: Correlation of clinical potency and in vitro effects. Arch. Dermatol. Res. 2006, 298, 23-30. [CrossRef]

72. Weber, T.M.; Ceilley, R.I.; Buerger, A.; Kolbe, L.; Trookman, N.S.; Rizer, R.L.; Schoelermann, A. Skin tolerance, efficacy, and quality of life of patients with red facial skin using a skin care regimen containing Licochalcone A. J. Cosmet. Dermatol. 2006, 5, 227-232. [CrossRef]

73. Afreen, F.; Zobayed, S.M.A.; Kozai, T. Melatonin in Glycyrrhiza uralensis: Response of plant roots to spectral quality of light and UV-B radiation. J. Pineal Res. 2006, 41, 108-115. [CrossRef]

74. Sharma, S.; Vasudeva, N.; Singh, S.; Das, S. Formulation and evaluation of post laser herbal cream. Int. J. Green Pharm. 2018, 12, 90-94. 
75. González-Minero, F.J.; Bravo-Díaz, L. The Use of Plants in Skin-Care Products, Cosmetics and Fragrances: Past and Present. Cosmetics 2018, 5, 50. [CrossRef]

76. Rackova, L.; Jancinova, V.; Petrikova, M.; Drabikova, K.; Nosal, R.; Stefek, M.; Kostalova, D.; Pronayova, N.; Kovacova, M Mechanism of anti-inflammatory action of liquorice extract and glycyrrhizin. Nat. Prod. Res. 2007, 21, 1234-1241. [CrossRef]

77. Martins, N.; Barros, L.; Duenas, M.; Santos-Buelga, C.; Ferreira, I.C.F.R. Characterization of phenolic compounds and antioxidant properties of Glycyrrhiza glabra L. rhizomes and roots. RSC Adv. 2015, 5, 26991-26997. [CrossRef]

78. Haraguchi, H.; Ishikawa, H.; Mizutani, K.; Tamura, Y.; Kinoshita, T. Antioxidative and superoxide scavenging activities of retrochalcones in Glycyrrhiza inflata. Bioorg. Med. Chem. 1998, 6, 339-347. [CrossRef]

79. Biondi, D.M.; Rocco, C.; Ruberto, G. New dihydrostilbene derivatives from the leaves of Glycyrrhiza glabra and evaluation of their antioxidant activity. J. Nat. Prod. 2003, 66, 477-480. [CrossRef] [PubMed]

80. Morteza-Semnani, K.; Saeedi, M.; Shahnavaz, B. Comparison of antioxidant activity of extract from roots of licorice (Glycyrrhiza glabra L.) to commercial antioxidants in $2 \%$ hydroquinone cream. J. Cosmet. Sci. 2003, 54, 551-558.

81. Niziol-Lukaszewska, Z.; Bujak, T. Saponins as Natural Raw Materials for Increasing the Safety of Bodywash Cosmetic Use. J. Surfactants Deterg. 2018, 21,767-776. [CrossRef]

82. Rozi, P.; Abuduwaili, A.; Ma, S.; Bao, X.; Xu, H.; Zhu, J.; Yadikar, N.; Wang, J.; Yang, X.; Yili, A. Isolationscharacterizations and bioactivities of polysaccharides from the seeds of three species Glycyrrhiza. Int. J. Biol. Macromol. 2020, 145, 364-371. [CrossRef] [PubMed]

83. Bhide, M.M.; Nitave, S.A. Formulation and evaluation of polyherbal cosmetic cream. World J. Pharm. Pharm. Sci. 2016, 5, 1527-1536.

84. Shivakant, S.; Kaushelendra, M.; Singhai, A.K.; Purnima, S.; Nayak, S. Hair care: From natural ingredients. Eur. J. Biomed. Pharm. Sci. 2020, 7, 401-409.

85. Utami, S.M.; Djajadisastra, J.; Saputri, F.C. Using hair growth activity, physical stability, and safety tests to study hair tonics containing ethanol extract of licorice (Glycyrrhiza glabra Linn.). Int. J. Appl. Pharm. 2017, 9, 44-48. [CrossRef]

86. Anand, P.; Murthy, A.R.; Sharma, G. Quality assessment of Yashtimadhukadi taila: Ayurveda remedy for Khalitya (hair fall). Int J. Green Pharm. 2018, 12, S722-S727.

87. Bhavani, M.D.; Sridurga, C. Analytical study of Tiladi Taila-A good remedy for hair fall. World J. Pharm. Res. 2017, 6, 1586-1593. [CrossRef]

88. Huang, B.; Kang, B.-G.; Wang, Z.; Lim, S.S. Effect of ethanol extract of plant mixture on hair regeneration in human dermal papilla cells and C57BL/6J mice. J. Med. Plants Res. 2015, 9, 1103-1110. [CrossRef]

89. Schweiger, D.; Rippke, F.; Drescher, P.; Braren, S.; Luettke, J.; Filbry, A.; Max, H. Highly efficient rinse-off/leave-on scalp care treatments to reduce moderate to severe dandruff. J. Cosmet. Dermatol. Sci. Appl. 2013, 3, 46-55. [CrossRef]

90. Mishra, R.C.; Kumari, R.; Iqbal, Z.; Rizvi, M.M.A.; Yadav, J.P. Synthesis, characterization, comparative antidandruff efficacy and cytotoxicity studies of biosynthesized silver nanoparticles by using Glycyrrhiza glabra root. Adv. Sci. Eng. Med. 2020, 12, 156-162 [CrossRef]

91. Keshri, P.; Khare, E. Antiacne synergistic herbal face wash: Formulation and evaluation. World J. Pharm. Res. 2020, 9, 1899-1907. [CrossRef]

92. Nakyai, W.; Pabuprapap, W.; Sroimee, W.; Ajavakom, V.; Yingyongnarongkul, B.-e.; Suksamrarn, A. Anti-Acne Vulgaris Potential of the Ethanolic Extract of Mesua ferrea L. Flowers. Cosmetics 2021, 8, 107. [CrossRef]

93. Nam, C.; Kim, S.; Sim, Y.; Chang, I. Anti-acne effects of Oriental herb extracts: A novel screening method to select anti-acne agents. Skin Pharmacol. Physiol. 2003, 16, 84-90. [CrossRef]

94. Reuter, J.; Merfort, I.; Schempp, C.M. Botanicals in dermatology: An evidence-based review. Am. J. Clin. Dermatol. 2010, 11, 247-267. [CrossRef] [PubMed]

95. Rasheed, A.; Shama, S.N.; Joy, J.M.; Reddy, B.S.; Roja, C. Formulation and evaluation of herbal anti-acne moisturizer. Pak. J. Pharm. Sci. 2012, 25, 867-870. [PubMed]

96. Nand, P.; Drabu, S.; Gupta, R.K.; Bhatnagar, A.; Ali, R. In vitro and in vivo assessment of polyherbal topical gel formulation for the treatment of acne vulgaris. Int. J. Drug Deliv. 2012, 4, 434-442.

97. Nand, P.; Drabu, S.; Gupta, R.K. Phytochemical and antimicrobial screening of medicinal plants for the treatment of acne. Indian J. Nat. Prod. Resour. 2012, 3, 28-32.

98. Sravani, L.V.; Rao, C.B.; Babu, R.K.D. Anti-acne activity of lipido-sterolic extract of serenoa repens and hydro-alcoholic extract of Gycyrrhiza glabra in Syrian hamster ear model. Indo Am. J. Pharm. Sci. 2017, 4, 2641-2650. [CrossRef]

99. Lakshmi, J.N.; Supriya, P.; Soumya, P.L.; Vandana, P.; Babu, A.N. Pharmacological evaluation of liquorice for various dermatological disorders in mice. Int. J. Pharm. Biol. Sci. 2019, 9, 1253-1259. [CrossRef]

100. Rekha, N.; Austin, A. In vitro study on the anti-Acne property of ayurvedic soap and body wash. World J. Pharm. Res. 2017, 6, 865-870. [CrossRef]

101. Koli, D.S.; Mane, A.N.; Kumbhar, V.B.; Shaha, K.S. Formulation \& evaluation of herbal anti-acne face wash. World J. Pharm. Pharm. Sci. 2016, 5, 2001-2007. [CrossRef]

102. Wagh, V.; Shaikh, S.; Maynale, S.S.; Mhaske, N. Preparation and evaluation of marigold, liquorice and corange peel extract containing herbal face wash. World J. Pharm. Res. 2015, 4, 1808-1812. 
103. Shivatare, R.S.; Kewatkar, S.M.; Lohakare, P.; Bhutale, N.; Musale, R.; Choudhary, D.; Ganu, G.; Nagore, D.H. Anti-inflammatory, anti-oxidant and anti-microbial properties of polyherbal formulation in acne treatment. Int. J. Pharm. Sci. Rev. Res. 2020, 62, 73-77.

104. Yang, G.; Lee, H.E.; Yeon, S.H.; Kang, H.C.; Cho, Y.-Y.; Lee, H.S.; Zouboulis, C.C.; Han, S.-H.; Lee, J.-H.; Lee, J.Y. Licochalcone A attenuates acne symptoms mediated by suppression of NLRP3 inflammasome. Phytother. Res. 2018, 32, 2551-2559. [CrossRef] [PubMed]

105. Nazari, S.; Rameshrad, M.; Hosseinzadeh, H. Toxicological Effects of Glycyrrhiza glabra (Licorice): A Review. Phytother. Res. 2017, 31, 1635-1650. [CrossRef] [PubMed] 